Kamala K. Hashimova

DOI: 10.25045/jpis.v07.i2.09

Institute of Information Technology of ANAS, Baku, Azerbaijan

commerce@iit.ab.az

\title{
PROSPECTS OF ADVERTISING-MARKETING OPTIMIZATION OF THE WEBSITES DURING THE SEARCH
}

The paper conducts the optimization of advertising-marketing on internet while searching. The interaction between the customers and consumers during the optimization is investigated, and positive effect of optimization on the economy is presented.

Keywords: advertising-marketing, Internet, marketing optimization, SAS, SEO, RTB.

\section{Introduction}

Advertisements can be found in any area of the economy. In particular, the effectiveness of advertising should be considered on the Internet. As the number of Internet users is increased, optimization of advertising - marketing attaches importance. Executives for advertising-marketing are chaired the organization as a whole and ensure its effectiveness. Effective advertisingmarketing leads to an increase in sales of the advertised product that has a positive impact on the economic development of the country.

Currently, the economy is hesitant area to be approached by everyone. The increase in the number of online users, assimilating marketing, involving new generation to the economy is satisfactory. Today, optimizing marketing strategy is of great importance. During the optimization of marketing should be based on several stages. These stages are very effective economically [1] .

$>$ Optimizing key marketing aspects of the acceleration-PPC (Pay Per Click);

$>$ Lead generation experience;

$>$ User Experience.

\section{The importance of PPC optimizing}

The main purpose of algorithms complexity is competitiveness. The need for PPC optimization has a few reasons:

- Usage of high-quality algorithm accounts;

- How consumers search for products and services;

- Lack of delay.

Optimization of PPC pages is important for attracting new customers. This method gives a rise to progress quickly, non-optimized pages lose customer.

Table 1.

Comparison of an optimized page to non-optimized one

\begin{tabular}{|c|c|}
\hline Before page optimizing & After page optimizing \\
\hline $\begin{array}{ll}- & \text { Having too much access; } \\
- & \text { Not-responding page for a long time; } \\
- & \text { Asking users for filling the complex forms; } \\
- & \text { Lack of unformatted key words among the } \\
& \text { technical information; } \\
- & \text { Impact on users with an uncertain call. }\end{array}$ & $\begin{array}{l}\text { - Frequent apply to users by reducing the } \\
\text { number of access points; } \\
\text { - Collect purposeful pages to memory; } \\
\text { - } \\
\text { Reduce to a minimum the amount of the } \\
\text { form; } \\
\text { - Use of key words on Heading and list; } \\
\text { - Involve users with an attractive title; } \\
\text { - Set a confidential relationship with the other } \\
\text { party by providing warranty, certificate } \\
\text { printing and indication of the reliability. }\end{array}$ \\
\hline
\end{tabular}


During advertising-marketing on the Internet, to develop site's unique strategy optimization is of important for users. Small changes can give a different result in search engine systems and optimization. Search optimization - it's the top position of the site for effective surveys in search engines.

Visitors of the site in search engines are high-quality and targeted audiences.

Users requesting for search queries in search database state their intentions in a commodity, service or in information. During the search through the site, they immediately get the desired product or service they are able to order. Search databases show the outputs of search according to the specified rules: sites suiting for search algorithm, covering user survey maximum are on the first place. In addition, algorithm estimates the site taking into account all the features, such as composition, structure, and technical aspects, if all the requirements of search algorithms met with search results and site to be adapted in accordance with them, position of the site will increase significantly. During the optimization of advertising-marketing on the Internet, the search is carried out on the request of "the core of requests" (performance list, search queries when the potential customers apply search engine) [2].

The features of search optimization in the Internet advertising-marketing:

$>$ Scope of the audience - interested in a search engine query, which includes user's product, service or information. Handy search engine sites can be used to buy the products or to order services.

$>$ Cheap price attracts customer - compared to traditional advertising channels, customer involvement embraces television, radio and the press.

$>$ While Internet advertising-marketing search optimization requires small number of expenses, and brings relatively numerous and qualitative audience to the site.

Commencing from the design, the internet optimization requires a huge content and a rich web structure. Designer uses relevant methods to provide the users' needs, respond to the information in required form and carefully learn easy navigation.

The data is collected in a website in accordance with the legislation. Management board is responsible for the confidentiality of the data. Database compiles collected or uncollected data on identifying personality and used, if necessary. Certain identity implies the name, mailing address, telephone number, e-mail and the IP address. If the number of visitors accessed a website and their presence time is unknown, this case is called data on the personal identification is non-available. As other databases, queries between users and customers, and reviews can be shown.

Web-browser is a device used to stream the data to the web-server and accessing to website. It embraces volume, output of the used and transmitted data, referring domains and data of IP addresses stored on the server file.

Those who are willing to innovate to the trade over the Internet, to develop new technologies, and new projects, to share, and to train producers should be aware of the followings [3].

- $\quad \boldsymbol{S E O}$ (Search Engine Optimization) - web sites, search engine optimization;

- $\quad \boldsymbol{R} T \boldsymbol{B}$ (Real Time Bidding) - new technology which constitutes the real-time ad auction announcements of online advertising;

- $\quad \boldsymbol{S E M}$ (Search Engine Marketing) - advertising, marketing services on search engines;

- $\mathbf{S M M}$ (Social Media Marketing) - Social media that is used by many people, i.e. marketing, advertising and promotional services over networks;

- Online advertising - boosting to promotional videos, mass e-mail and SMS fulfillments, and activities such as online request and promotional marketing. 


\section{SEO search optimization}

SEO (search engine optimization) or website optimization - provides forefront while searching. When a customer is looking for information about a service or product on search sites, he uses key words then a few site names appear on the screen. Forefront sites must be applied. This method of online advertising is one of the most effective ways to attract customers.

There are a few types of appearance of the page name in the first page of search results. Some of the steps that must be taken into account in order to achieve outcome, are divided into two parts:

1) Internal optimization;

2) External optimization.

Internal optimization includes the work with customer, site structure, and links. External optimization is increasing the link number. This process has been ranked by means of all search engines. Ranking is definition of the line and response for user in search system according to rank, authority, or eligibility.

By learning ranking mechanism many questions can be responded. For example, two similar- search site on the same topic; one in the front at the top, and the other is located on the third page. Usually, all the sites are indexed by search engines. Each search system conducts a search according its principles. The difference is that, in fact, the sites lies in different places in different search systems. In case your site is trusted by the search systems, changing the algorithm will not change its position. It plays a key role in the internal and external ranking. Ranking is based on site relevance. Each search system has its own principles for survey adoption. There are two important criteria in establishing compliance with the survey of the site.

The first criterion is ranked by its content. The eligibility is derived from the lexicalsemantic analysis of the text placed on the site [5].

The second criterion is a mere formality. This conformity determination of eligibility is based on algorithms of search systems that have been included in the program. The result of evaluation is not stable, and has a variable growth. Occasionally, the employees change the system algorithms, in order not to access the wrong sites through the barrier filters. If the site is trusted by the search systems then the change of algorithm will not change its position in the ranking.

Distributed or centralized information processing exists at sales outlets in order to provide customer services. Operational reporting and authorization data storage are managed by means of the analytical sub-system.

\section{RTB}

Real Time Bidding - new technology is eligible for organizing auctions of advertising in the field of online advertising in real time. RTB had a major influence on the digital advertising market in the world. RTB is widely used in the USA being the leaders at advertising technology platform. Though European Union accepts RTB more slowly, but the demand for mobile connectivity is increasing here. RTB helps advertising deploy on the Internet.

Advertising network providing RTB service after receiving a request for ad display:

1. Survey is classified according to the maximum number of parameters; data about the user (if enabled), the area which he included, time, and the target is accepted prior to purchase.

2. Additional data is collected from the base of selected ads mechanism according to the particular criteria.

3. Survey response on user is transmitted to the advertiser and the share is obtained. By means of this share they get opportunity to next display.

4. The highest share is determined among the obtained responses, the next stage is established.

5. Announcement is bought from the winner advertiser and given to the user as a response to the request. 


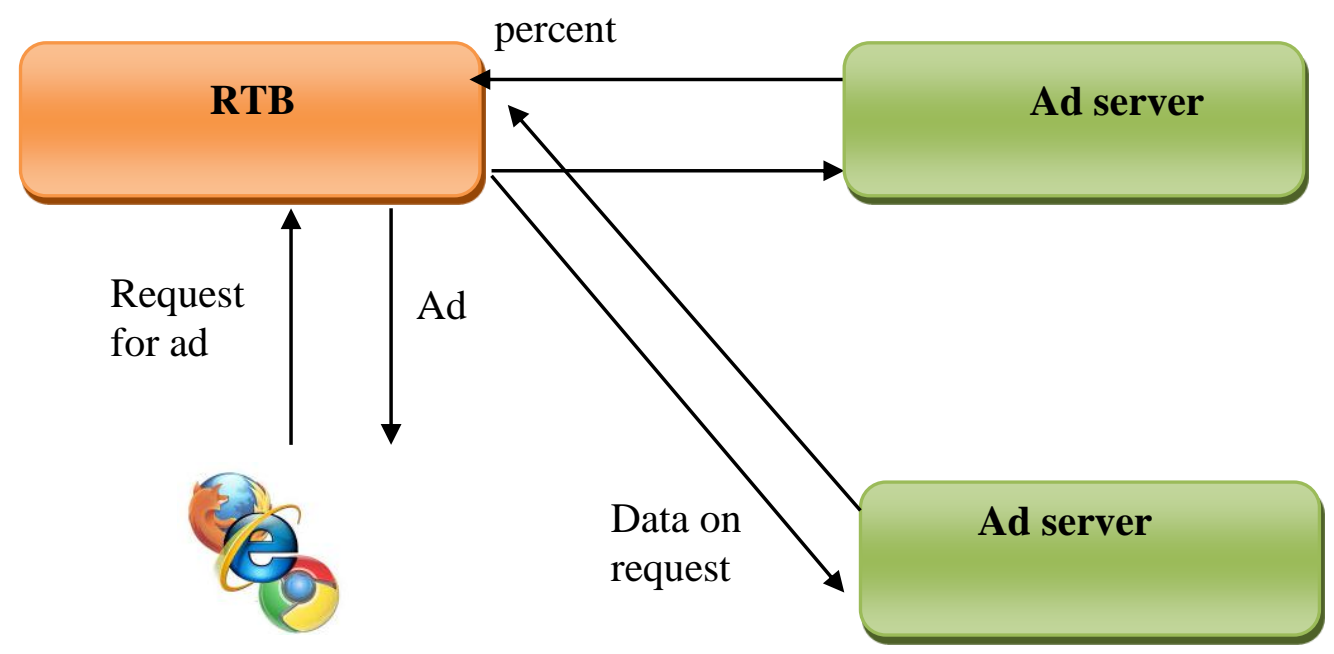

Figure 1. Advertising and marketing of search optimization

Caution on the following areas of advertising-marketing search optimization:

- Motion;

- Contact form;

- Speed;

- Title.

Increasing the number of applications, optimization location on the first page makes positive impact on the audience. Recurrence of the pages should be persistent [6].

\section{What is marketing optimization?}

Marketing optimization is the process of improvement of the organization's marketing performance in order to achieve maximum outputs. Marketing optimization is widely used in the development of marketing.

The theory of the Web-optimization hierarchy:

In the absence of Websites (WPO - web presence optimization), idea of creating a hierarchy of optimization came from the belief. While search, ground-based principle is required before achieving success.

Usual search is at the four intersections - optimized marketing, social media, all changes of Google algorithm and marketing.

Total tactics in marketing is comprehensive marketing optimization. If the optimized marketing to be applied during campaign results will be as follows:

- Improved and extended ranking while usual search;

- Positive impressions;

- Click-increased probability;

- Changes;

Optimized marketing plan covers Google algorithm with four major changes since previous year:

a) About updates - press releases on Google innovations, blogs, case studies, latest news and events;

b) Google upgrade - is the filter of the given search. Optimized content distributed for true, reliable sources, to assist for establishing of strong anti-citations;

c) Google + - is a social and social-media network about the links. These links prove the demand is provided. Google's social network, Google+ and its algorithm actually takes into account the search;

d) Supremacy of Your World request - than any other social network, for example, including 
Facebook or Twitter, Google + is more reliable. A long-term service can be obtained here by openly sharing ideas [7].

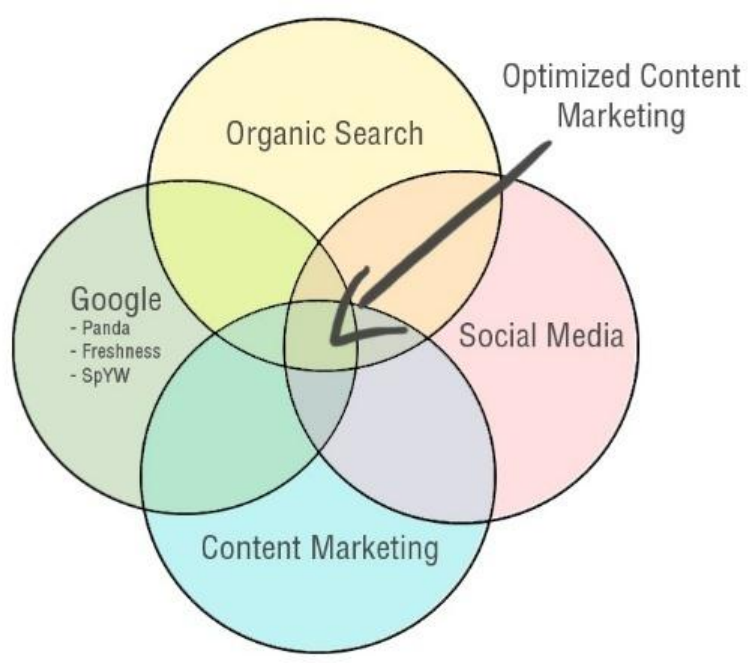

Figure 2. Intersection of search optimization

\section{How does SAS assist for Marketing optimization?}

SAS (Statistical Analysis System) provides business ties by delivering optimization and identifying customers, and keeps in touch with each of them separately. For example, taking into account the probability of the responses to customers, outputs expenses, political reflection, resource, budget constraints, etc.

\section{Why SAS Marketing Optimization is important?}

Transmitting the optimization, SAS increases the ratings of marketing campaigns by allowing each customer to identify the best proposals. Moreover, it eliminates business constraints such as budgets distribution increasing the capacity of the channel contacts, changing the outputs in link policy by allowing discussion [8].

SAS marketing can be used by marketing campaign managers, business analysts, managers for segment and analysts. The effect of the optimization is designed to give a guarantee the huge economic results of marketing.

Relying on marketing, the organization representative directly messages the vulnerable customer by creating a noisy marketing in order to present the least as much. In this case, mutual effect that forecasts segmentation, modeling and testing can improve the efficiency can be improved. The marketing result within a day is not clear. Marketers should study trade issues competing through sections.

Being aware of the numerous marketing programs for limitations, budget oversight and customer relations should be specially carried out. Diversified ventures lay across the choice before millions of customers.

In order to maximize income or (Return On Investment - ROI) within a budget, it is necessary to carry out policy with experience and intuition. As a result of maximum extent of the relationship with each customer individually, and careful approach in presenting SAS Optimization, the profit of the organization is maximized while applying mathematical methods.

\section{Key words option}

Key words option is the key phase in SEO. If there is no right choice it is difficult for the consumer to get high rankings in search engines. Wrong choice of key words or phrases may yield unexpected results. Next steps should be considered during key words option: 
1. The brain product - must take into account that potential buyers will write the name of the product (pronounced options, different word forms, synonyms) due to searching for the prices of goods and find for the proposed product.

2. New and potential buyers' request - is the method of posting as more keywords as possible into the list. By means of website for raise of traffic is essential to increase sale amount.

3. Action directions option - is to draw up the table or graph. Action direction reflects traffic comparison, its relevance and changes to them, helps to gather additional information to make the right decision.

4. Execution, verification and analysis - selected keywords and programs are designed to track included web-changes.

5. Special program - analytic programs are available to measure traffic amount and track of changes in sites. For example, Wordtracker (www.wordtracker.com) and Overture (www.overture.com) offer information on the number of requests made by users. Using the software database the appropriate keywords for any business can be determined.

Table 2.

Keywords selected by means of software

\begin{tabular}{lllllll}
\hline Keyword & Volume & KEI & Comp. & IAAT & IT & Country \\
\hline inexistent & 26601171 & 96.57 & 7.33 & 89 & 197753 & GLOBAL \\
movies & 20226091 & 80.57 & 51.6 & 712635 & 199564908 & GLOBAL \\
youtube & 10585128 & 79.06 & 49.76 & 602806 & 44606390 & GLOBAL \\
facebook & 7844123 & 78.03 & 49.94 & 612976 & 52456127 & GLOBAL \\
google & 7579933 & 75.89 & 56.81 & 1109804 & 189408257 & GLOBAL \\
followerscounter & 6628518 & 97.92 & 3.21 & 2 & 18 & GLOBAL \\
comcom & 5942025 & 93.87 & 9.88 & 352 & 105824 & GLOBAL \\
craigslist & 5811554 & 85.2 & 27.52 & 39392 & 2985349 & GLOBAL \\
search & 5597574 & 74.72 & 57.15 & 1140637 & 1056711615 & GLOBAL \\
kinox & 4833876 & 91.37 & 13.85 & 1667 & 263467 & GLOBAL \\
\hline
\end{tabular}

Both programs are completely suitable for comparison of amount and results. Overture unites short and meaningful ideas. Though the volume of Wordtracker is small, it provides detailed information [9]. For ex:

Overture portal

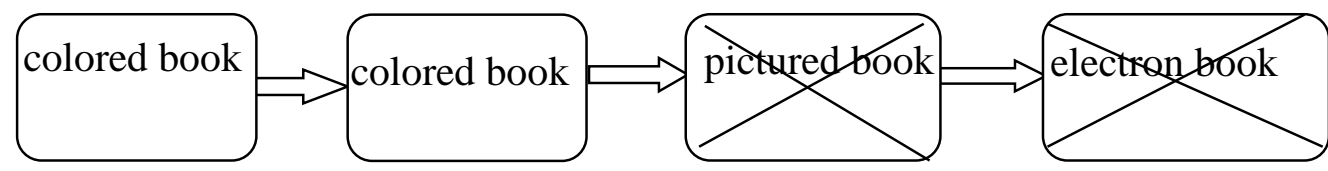

Wordtracker portal

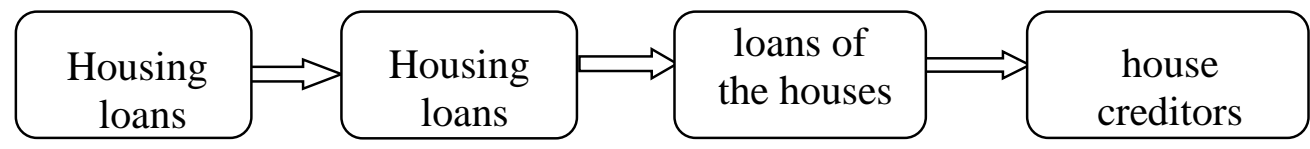

Figure 3. Result indicators of search web-sites 
Requests appear briefly in large letters, in plural and word form. Data accuracy rate is more useful for the analysis of surveys. Usage of large letters in search engines in advertising-marketing on the Internet does not give a different result. Plural forms of words collects brief opinions of different surveys. When we compare the number of users who have the same requests at the same time, the result can be extremely inaccurate. The preference is to use different words.

Directing consists of usual measure of the traffic amount and optimal key words. Efficiency rate is measured by the percentage of users who are shopping by applying:

- estimating the number of users who applied within a month according to proposed traffic-survey;

- estimating the customers - average assessment of buyer's comparison in search of cheaper-expensive;

- Key words competitiveness - calculation degree of the competition for chosen word. It is the financial parameter in SEO sector due to number of competitors including the impact of the references.

If the algorithm was on the focus during investigation of the optimization in search engines in advertising-marketing on the Internet, in recent years, it is enough to make use of search marketing aids. The creation of a normal relationship with readers is very important in optimization.

User should take into account the limited opportunities when choosing keywords. For example, survey for "small tablets" will be a lower level of competition. Optimization of the largest surveys often faces with big stuck. Usually permanent buyers applying to the site with accurate and concrete key words get limited number of results. Less sorting of information is readily available.

There is countless optimizers started creating content optimization. They think of how many keywords they use and where to post them. Sometimes, being addicted to the keywords, the creators of the web-resource forget about the quality of the content. In this case, they do not achieve the sought result.

Sometimes during internet advertising-marketing optimization we come across meaning lines that are not similar. If the user quits without being acquainted or without attempting to its usage it is considered negative. The coordination should be appropriate when the keyword relevant to the content is typed.

Search engines are complicated and important for creating websites. Establishing stable flow of traffic in order to get the effectiveness of websites optimization is enough on the Internet advertising-marketing. It is known that users are using search engines basically. Site which referred by a user during advertising-marketing searching optimization should inform him. Home page of the site should awake imagination on the user on the site, and guide him how to find out useful data [10].

Sections cover a variety of site topics, sub-sections provide more detailed information on the topics. Everything may seem simple, but experience shows against. For this reason, the scheme of the site is developed in advance. Keywords can define the weight of the site. Sites are associated with one another during the optimization.

The location of the pages in hosting is not sigificant. Site design and internal posting of sections may be different depending on site creation, but the overall structure of the site must comply with this model. 


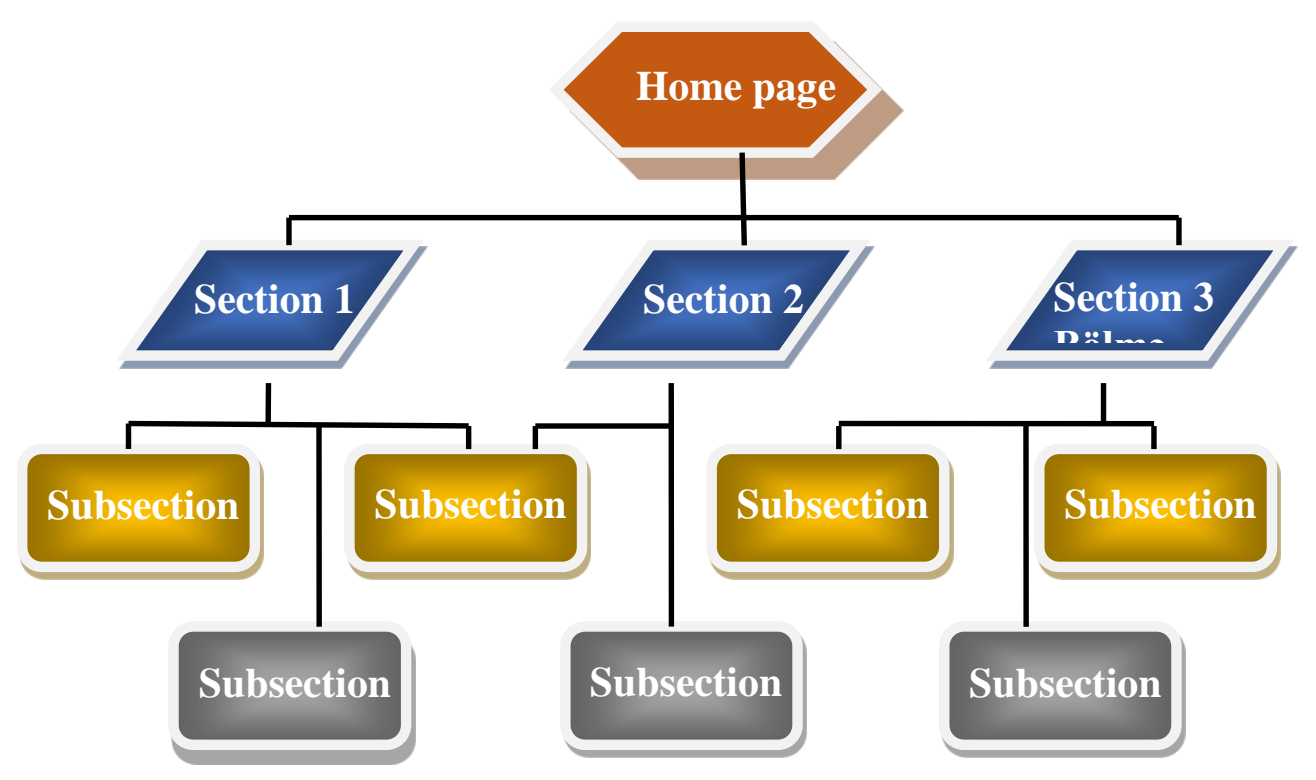

Figure 3. The simple structure of the site and its units

Three-level model structure of a simple site and its sections:

Section 1 - Home page

Section 2 - Sections on topics

Section 3 - small subsections

The level of the site is identified by the number of citations.

First level - home page;

Second level - citations to home page;

Third level - citations from the second level pages. Internet:

Thus, two issues should be considered during advertising -marketing optimization on the

a) To involve users to use search engine by writing correct title relevant to request;

b) To turn a regular readers into a buyer.

The full download of the page is more important for users. Most part of users leaves the site when it has not downloaded within three seconds [11].

During the estimation of the web-sites algorithms, search engines and their indexes are utilized. As the SEO is constantly developing those who are engaged in websites should cope with these changes. A lot of search assessment methods are urgent today - but after a couple of years can be completely out of date. Moreover, these methods that do not produce positive results two years ago, even now can meet the demand.

\section{Conclusion}

Search optimization of advertising-marketing on the Internet highlights the visibility of company in the network with overall approach and without requiring large expenditures. Organization should think not only as a supplier of goods and services, but also think about its image.

One of the country's economies is advertising- marketing on the Internet. Accordingly, advertising-marketing organization and its effectiveness is necessary. Currently, Internet advertising embraces vital ads functions and most attendees of market utilizes it.

Each user of the Internet should provide his safety. When we use the information a page shall open taking into account the compatibility of the brief announcements with the requested data during the optimization. 


\section{References}

1. Golik V.S. Efficiency of internet-marketing in business, Dikta, 2008, 196. p.

2. Baykov V. D. Internet: searching for information on promotion of sites, St. Petersburgh, 2000, $288 \mathrm{p}$.

3. Lunkim T. Traditional System of Kuki Administration, in T. Haokip (ed.). The Kukis of Northeast India: Politics and Culture, New Delhi: Bookwell, 2013, Chapter 1, 46 p.

4. Sevostyanov I. O. Searching optimiziation. Practical management for promotion of sites on Internet, St. Petersburgh, 2010, p. 182-187.

5. Belch G., Advertising and Promotion: An Integrated Marketing Communications, 4th ed, NY, McGraw-Hill Book Co, 2003, 62 p.

6. Cherniy A.I., World information market // NTI in abroad, M., 1998, p. 230-234.

7. http://www.proview.ru/simple_and_quick_solution_of_main_tasks_in_search

8. http://www.proview.ru/how_to_conduct_keyword_research

9. http://www.bruceclay.com/jp

10. http://www.seoded.ru/beginner/raskrutka.html

11. http://www.ashmanov.com/marketing/seo/what 